\title{
Linhagens de alface-crespa para o verão resistentes ao Meloidogyne javanica e ao vírus mosaico-da-alface
}

\author{
Renata Rodrigues Silva(1), Luiz Antônio Augusto Gomes ${ }^{(1)}$, Aline Beraldo Monteiro(1), Wilson Roberto Maluf(1), \\ José Luiz Sandes de Carvalho Filho(1) e João Aguilar Massaroto(2)
}

(1)Universidade Federal de Lavras, Departamento de Agricultura, Caixa Postal 3.037, CEP 37200-000, Lavras, MG. E-mail: rrs.ufla@gmail.com, laagomes@ufla.br, alinebm_agro@yahoo.com.br, wrmaluf@ufla.br, jlsandes2000@yahoo.com.br (2)Universidade do Estado do Mato Grosso, Departamento de Agronomia, Rodovia MT 208, Km 147, CEP 78580-000 Alta Floresta, MT. E-mail: jamassaroto@yahoo.com.br

Resumo - $\mathrm{O}$ objetivo deste trabalho foi selecionar famílias $\mathrm{F}_{4}$ de alface, oriundas do cruzamento entre as cultivares Verônica e Salinas 88, para o cultivo no verão, com relação ao tipo de folha, e à resistência ao Lettuce mosaic virus (LMV) e ao nematóide-das-galhas Meloidogyne javanica. Primeiramente, avaliaram-se a coloração da folha, tipos de borda e limbo foliares, além da tolerância ao calor no campo, em blocos ao acaso compostos pelas 15 famílias $\mathrm{F}_{4}$ previamente selecionadas, pelas cultivares parentais e pela cultivar testemunha Regina 71 (folhas lisas e tolerante ao calor), com cinco repetições e oito plantas por parcela. Na segunda etapa, as famílias foram avaliadas quanto à resistência ao LMV e ao nematóide-das-galhas, em bandejas de 128 células acondicionadas em estufa. As médias das notas atribuídas a cada família foram comparadas às médias de cada cultivar parental pelo teste de Dunnet (5\%). A família AFX007B-140-21, homozigota resistente aos nematóides e ao LMV e, também, tolerante ao calor, foi a mais promissora. O cruzamento entre uma cultivar de folhas crespas e soltas com uma de folhas crespas e repolhuda, pode originar linhagens promissoras tanto de folhas crespas quanto de folhas lisas.

Termos para indexação: Lactuca sativa, florescimento precoce, LMV, melhoramento, nematóide-das-galhas.

\section{Lineages of crisp-leaf lettuce for summer cropping resistant to Meloidogyne javanica and to Lettuce mosaic virus}

\begin{abstract}
The aim of this work was to select $\mathrm{F}_{4}$ lettuce families, derived from the cross 'Veronica' $\mathrm{x}$ 'Salinas 88', for summer cropping, type of leaves, and for resistance to Meloidogyne javanica and to Lettuce mosaic virus (LMV). First, evaluations were made for leaf colour, leaf limb, border type, and heat tolerance in the field, in a complete blocks desing, in $15 \mathrm{~F}_{4}$ families previously selected, parent cultivars and, as control, the cultivar Regina 71 (butterleaf and tolerant to heat). Five replicates and eight plants per plot were used. As second step, the families were evaluated in greenhouse, in 128-cell expanded polystyrene trays, for resistance to LMV and root-knot nematodes. Score means of each family were compared to the means of each parental cultivar by Dunnett test at 5\% probability. Family AFX007B-140-21, homozygous for root-knot nematodes, for LMV and heat tolerant, was the most promising. The cross between crisp and butter leaf cultivars can originate promising lineages both with crisp and butter leaves.
\end{abstract}

Index terms: Lactuca sativa, early bolting, LMV, breeding, root-knot nematodes.

\section{Introdução}

Entre os grupos de alface mais consumidos no país, o de folhas crespas vem crescendo consideravelmente nos últimos anos e correspondeu a $46,43 \%$ do volume comercializado no ano de 2006, pela Ceagesp (Agrianual, 2008), o que evidencia a importância deste tipo de alface.

Embora os trabalhos de melhoramento de alface no Brasil tenham alcançado progressos significativos e contribuído para o plantio desta espécie, em praticamente todo território nacional, alguns problemas ainda persistem, entre os quais, se destacam - em condições de verão ou nas regiões com temperaturas mais elevadas - a ocorrência de florescimento precoce e a incidência de patógenos como os nematóides e o vírus mosaico-da-folha.

Por ser cultura originária de clima ameno, a alface não produz bem em condições de altas temperaturas (Cásseres, 1980). Dias longos, associados à temperatura elevada, aceleram o processo do florescimento precoce, que depende da cultivar (Nagai, 1980). Ao passar para 
a fase reprodutiva, antes mesmo de emitir a haste floral, inicia-se a produção de látex pela planta, que the confere um sabor amargo e a torna imprópria para o comércio (Cásseres, 1980).

Estudos sobre a herança do florescimento em alface (Silva et al., 1999) evidenciaram a existência de herdabilidade alta no sentido amplo e no restrito, além da ocorrência de segregação transgressiva. Esses estudos demonstram a possibilidade de sucesso na obtenção de linhagens mais tolerantes ao florescimento precoce, a partir da seleção em populações segregantes, oriundas do cruzamento entre pais contrastantes para a característica.

Alguns autores, como Silveira et al. (2002) e Fiorini et al. (2005), obtiveram resultados que confirmam os estudos de Nagai (1979) e Silva et al. (1999), e identificaram indivíduos com florescimento mais lento.

A identificação de fontes de resistência ao nematóide-das-galhas, preferencialmente entre as cultivares comerciais, bem como a busca pelo desenvolvimento de cultivares resistentes, adaptadas às diversas condições brasileiras, têm sido as preocupações de alguns pesquisadores, especialmente a partir do início da década de 1990 (Fiorini et al., 2007). Estudos de herança para esse caráter, realizados a partir do cruzamento entre as cultivares Regina 71 (suscetível) e Grand Rapids (resistente), evidenciaram que tanto para Meloidogyne incognita (Gomes et al., 2000) quanto para M. javanica (Maluf et al., 2002), o controle genético é feito por um único loco gênico. Nesses estudos, foi mostrado, também, que o gene apresenta efeito predominantemente aditivo, com herdabilidade relativamente alta, no sentido amplo, o que facilita a seleção de novos genótipos resistentes. Outros trabalhos (Maluf et al., 2003; Carvalho Filho, 2006) evidenciaram a resistência da cultivar Salinas 88 ao $M$. incognita e ao M. javanica.

A produção de sementes de alface, assim como da própria alface oriunda de sementes produzidas no Brasil, era praticamente inviável até a década de 1960. Isto em razão da presença constante de inóculo do Lettuce mosaic virus (LMV), favorecida pelas condições ambientais ideais para atuação do seu vetor. A primeira cultivar nacional a ser lançada com resistência ao LMV foi a Brasil 48 do IAC (Instituto Agronômico, Campinas, SP), cuja fonte de resistência - o gene mol $^{1}$ (Nagai, 1979) - originou-se da 'Gallega de Invierno', material este de grande importância, a partir do qual muitas linhagens e cultivares comerciais foram obtidas. Outro material altamente resistente, em razão do gene $m^{2} l^{2}$, foi o 'PI 251245-9' (Lactuca serriola), mas que, por apresentar fortes características de planta selvagem, não foi comercialmente viável (Nagai \& Costa, 1971).

Por mais de 20 anos, a resistência genética condicionada pelos genes $\mathrm{mol}^{1}$ e $\mathrm{mol}^{2}$ foi classificada como durável, e foi responsável pela baixa incidência do mosaico-da-alface (LMV) no Brasil (Chung et al., 2007). A capacidade de diferentes estirpes do LMV de quebrar a resistência, conferida pelos genes $\mathrm{mol}^{1}$ e $m o l^{2}$, é empregada como base para a classificação do LMV em patótipos, dos quais são reconhecidos o I, II, III e IV, nas principais regiões produtoras de alface do mundo (Pink et al., 1992). No Brasil, foram identificados os patótipos II, IV (Stangarlin et al., 2000) e o patótipo III (Cossa et al., 2000).

A cultivar Salinas 88 , já comentada como resistente ao nematóide-das-galhas, apresenta também resistência ao LMV - patótipos I, II e III - e é portadora do gene recessivo $\mathrm{mol}^{2}$ (Stangarlin et al., 2000). Essa cultivar é do tipo americana, mas apresenta problemas de formação de cabeça em condições brasileiras, no entanto, é um material de grande importância para ser utilizado em programas de melhoramento.

$\mathrm{O}$ objetivo deste trabalho foi avaliar famílias $\mathrm{F}_{4}$ de alface, oriundas do cruzamento entre as cultivares Verônica e Salinas 88, para a seleção de famílias promissoras à obtenção de alface crespa para cultivo no verão, resistentes ao Meloidogyne javanica e ao vírus do mosaico-da-alface (LMV).

\section{Material e Métodos}

Oriundas do cruzamento 'Salinas 88' (tipo americana, com folhas verde-escuras, resistente ao nematóidedas-galhas e ao vírus do mosaico-da-alface - LMV, patótipos I, II e III, e sensível ao florescimento precoce) x 'Verônica' (com folhas crespas verde-claras, suscetível ao nematóide-das-galhas e ao LMV e tolerante ao florescimento precoce), 15 famílias $\mathrm{F}_{2: 4}$ de alface foram obtidas por meio de hibridações realizadas em campo, nas dependências da HortiAgro Sementes Ltda., no Município de Ijaci, MG, no ano de 2003 (altitude $920 \mathrm{~m}$, $21^{\circ} 14^{\prime} \mathrm{S}$ e $45^{\circ} \mathrm{W}$ ). As sementes $\mathrm{F}_{1}$ foram avançadas para $\mathrm{F}_{2}$, de forma semelhante, no ano seguinte. Uma 
amostra de sementes $\mathrm{F}_{2}$ foi colocada para germinar e, em seguida, 364 plantas $F_{2}$ com 31 plantas de cada um dos parentais foram avaliadas para a reação ao LMV e quanto à tolerância ao florescimento precoce. Nessa etapa, foram selecionadas 65 plantas $F_{2}$ resistentes ao LMV e tolerantes ao florescimento precoce, cujas sementes foram colhidas individualmente, para originar 65 famílias $\left(\mathrm{F}_{2: 3}\right)$. Seiscentos e noventa e cinco plantas $\mathrm{F}_{2: 3}$, com 87 plantas da cultivar Salinas 88 (padrão de resistência) e 138 plantas da Regina 71 (padrão de suscetibilidade) foram avaliadas quanto à reação ao nematóide-das-galhas Meloidogyne spp. (neste caso específico, utilizou-se uma mistura de espécies) $\mathrm{e}$, novamente, quanto à tolerância ao florescimento precoce. As 15 plantas selecionadas entre e dentro das famílias $\mathrm{F}_{2 \cdot 3}$, com superioridade nas duas características, foram colhidas separadamente e deram origem às 15 famílias $\mathrm{F}_{2: 4}$, que foram denominadas:

AFX007B-126-30, AFX007B-140-06, AFX007B-140-21, AFX007B-150-02, AFX007B-150-14, AFX007B-150-18, AFX007B-188-10, AFX007B-188-13, AFX007B-188-14, AFX007B-229-09, AFX007B-229-11, AFX007B-229-17, AFX007B-229-27, AFX007B-311-23 e AFX007B-75-05.

Tanto quanto à virose como quanto ao nematóide, a caracterização da reação das plantas foi realizada em bandejas de poliestireno expandido de 128 células, com substrato comercial Plantmax, acondicionadas em estufas, após inoculação artificial. Foi utilizada uma escala de notas de 1 (maior resistência) a 5 (maior suscetibilidade), com base nas intensidades de sintomas na parte aérea e de galhas nas raízes, respectivamente.

Nas avaliações da tolerância ao florescimento precoce, em condições de calor, as plantas de cada família foram analisadas individualmente, tendo-se contado o número de dias decorridos da semeadura até a primeira antese. Nessas avaliações, além dos dois parentais ('Salinas 88' e 'Verônica'), também foram incluídas, como testemunhas, as cultivares de alface Grand Rapids (com folhas crespas, resistente ao nematóide-das-galhas e sensível ao florescimento precoce) e Regina 71 (com folhas lisas, suscetível ao nematóide-das-galhas e tolerante ao florescimento precoce).

O trabalho foi conduzido em duas etapas: na primeira, foram avaliadas as características comercias e, na segunda, foram selecionadas as plantas por famílias resistentes aos dois patógenos.

A primeira etapa foi realizada em campo, tendose utilizado o delineamento em blocos ao acaso, com 5 repetições e 8 plantas por parcela, no total de 40 plantas por tratamento. Os tratamentos foram compostos pelas 15 famílias $F_{2: 4}$ ('Salinas $88^{\prime} \mathrm{x}$ 'Verônica') e as cultivares Verônica (folhas crespas e coloração verde-clara), Salinas 88 (tipo americana e de coloração verde-escura) e Regina 71 (folhas lisas e coloração verde-clara), incluídas no experimento como testemunhas. As mudas de alface foram obtidas em bandejas de poliestireno expandido de 128 células com substrato comercial Plantmax e transplantadas para o campo, no espaçamento $0,25 \mathrm{~m}$ entre plantas e 0,30 m entre fileiras. Aos 60 dias após o transplantio, procedeu-se à avaliação quanto às características comerciais (coloração das folhas e tipos de borda e de limbo foliar).

Para as avaliações dos tipos de borda e de limbo foliar, utilizou-se a escala de notas proposta por Fiorini et al. (2005), a seguir: 1, borda/limbo crespos; 2, borda/ limbo muito enrugados; 3 , borda/limbo enrugados; 4 , borda/limbo pouco enrugados; e 5 , borda/limbo lisos.

Uma escala de 1 a 3 foi utilizada para auxiliar na avaliação da coloração das plantas. As notas 1, 2 e 3 foram atribuídas a plantas com coloração verde-clara, verde intermediário e verde-escuro, respectivamente.

As notas médias (tipos de borda/limbo foliar e coloração das plantas), obtidas para cada uma das 15 famílias $\mathrm{F}_{2: 4}$, foram comparadas pelo teste de Dunnett, a $5 \%$ de probabilidade, com as notas médias obtidas pelas cultivares Verônica, Salinas 88 e Regina 71.

As plantas de alface foram mantidas no campo até o momento de se avaliar a tolerância ao florescimento precoce. Para cada uma das plantas, foi anotado o número de dias decorridos do transplantio até a primeira antese. Os valores médios obtidos para cada uma das famílias $\mathrm{F}_{2: 4}$ foram comparados, pelo teste de Dunnett, a 1 e $5 \%$ de probabilidade, com aqueles obtidos pelas testemunhas 'Grand Rapids' e 'Regina 71', sensível e tolerante ao florescimento precoce, respectivamente.

A segunda etapa do trabalho foi realizada em estufa e consistiu na realização de dois experimentos. O primeiro foi conduzido de $11 / 1$ a 20/3/2007, para avaliar a reação das 15 famílias $\mathrm{F}_{2: 4}$ de alface ao Meloidogyne javanica. O segundo experimento, realizado de $7 / 11$ a 19/12/2007, teve como finalidade avaliar a reação das 15 famílias $\mathrm{F}_{2: 4}$ de alface ao Lettuce mosaic virus - LMV. Em ambos os experimentos, a semeadura foi realizada em bandejas de poliestireno 
expandido, com 128 células e substrato comercial Plantmax, em delineamento experimental inteiramente ao acaso, com seis (primeiro experimento) ou cinco repetições (segundo experimento) e oito plantas por parcela. No primeiro experimento, os tratamentos foram compostos pelas 15 famílias $\mathrm{F}_{2: 4}$, pelos parentais 'Salinas $88^{\prime}$ (resistente ao M. javanica) e 'Verônica' (suscetível ao M.javanica). Os tratamentos do segundo experimento consistiram nas 15 famílias $\mathrm{F}_{2: 4}$, com os parentais 'Salinas 88 ' e 'Verônica', resistente e suscetível ao LMV - patótipos I, II e III, respectivamente, e 'Regina 71', hipersensível ao LMV e incluída para indicar o momento da avaliação.

A inoculação dos patógenos foi realizada aos 15 dias após a semeadura, com o auxílio de uma seringa veterinária, aplicados abaixo e ao lado de cada muda de alface, em suspensão com 600 ovos $\mathrm{mL}^{-1}$ de substrato.

A avaliação ocorreu aos 45 dias após a inoculação, momento em que a cultivar Regina começou a apresentar sintomas, e consistiu na determinação, para cada planta, do índice visual de galhas (IVG) e do número de galhas (NDG). Para a determinação do IVG, a planta foi retirada da bandeja, ainda com o torrão, teve o seu sistema radicular minuciosamente observado e recebeu uma nota de 1 a 5 , de acordo com intensidade de galhas. As notas foram atribuídas, como proposto por Fiorini et al. (2007): 1 , poucas galhas visíveis (menos de 5 galhas, com diâmetro $\leq 1 \mathrm{~mm}$ e não coalescentes); 2 , poucas galhas visíveis, porém, com 2 a 3 galhas com diâmetro $>1 \mathrm{~mm}$ a $\leq 3 \mathrm{~mm} ; 3$, mais de 6 a 20 galhas visíveis, em que $70 \%$ das galhas eram de tamanho médio e o restante de tamanho grande ( $>3 \mathrm{~mm}$ de diâmetro); 4, mais de 20 galhas visíveis, em que $50 \%$ das eram de tamanho grande e $40 \%$ eram coalescentes; e 5 , mais de 20 galhas visíveis, com mais de $70 \%$ de tamanho grande e mais de $50 \%$ coalescentes. Para a análise estatística, as notas atribuídas a cada planta foram transformadas em $\mathrm{x}^{0,5}$, e as médias de cada família foram comparadas pelo teste de Dunnett, a $5 \%$ de probabilidade, com ambos os parentais.

Para a determinação do NGD, cada planta foi retirada da bandeja e teve o sistema radicular cuidadosamente lavado em água parada, para o desprendimento do substrato. Em seguida, contou-se o número de galhas. As médias obtidas de cada família foram comparadas pelo teste de Dunnett, a 5\% de probabilidade, com ambos os parentais.

Como fonte de inóculo, utilizou-se o isolado LMV-Cf (sabidamente não pertencente ao patótipo
IV), fornecido pelo Departamento de Fitopatologia, da Universidade Federal de Lavras. As plantas de alface foram infectadas, mecanicamente, no estádio de 5-6 folhas verdadeiras (aproximadamente 20 dias após a semeadura) e, novamente, aos sete dias após a primeira inoculação do patógeno, como sugerido por Chung et al. (2007).

A avaliação foi realizada aos 25 dias após a inoculação, tendo-se atribuído a cada planta uma nota de 1 a 5 , como segue: 1 , planta imune, sem sintoma visível; 2 , planta com clareamento nas nervuras; 3 , planta com mosaico clorótico leve; 4, planta com mosaico bem desenvolvido; e 5, planta com mosaico amareladobolhoso e presença de deformação foliar. A nota média obtida em cada uma das famílias foi comparada, pelo teste de Dunnett, a 5\% de probabilidade, com as notas médias dos parentais.

\section{Resultados e Discussão}

Com relação ao tipo de borda das folhas, observou-se que as famílias AFX007B-229-09, AFX007B-229-11, AFX007B-229-17 e AFX007B-229-27 apresentaram médias de notas que não diferiram da testemunha 'Regina 71', ou seja, tipo de borda lisa (Tabela 1). As outras famílias apresentaram média de valores intermediários, maiores ou iguais aos da cultivar Salinas 88, o que não caracteriza folhas crespas, pois todas diferiram da cultivar Verônica. Dentro dessas famílias, no entanto, especialmente aquelas com valores médios menores, encontrou-se uma ou mais plantas que individualmente apresentaram nota semelhante à da cultivar Verônica (Tabela 2). Isto demonstra a existência de variabilidade quanto ao caráter entre e dentro das famílias. Plantas que obtiveram notas superiores à cultivar parental Salinas 88, são indicação também de que, provavelmente, exista segregação transgressiva quanto ao caráter (Ramalho et al., 2004).

No tipo de limbo foliar, as famílias AFX007B-126-30, AFX007B-229-09, AFX007B-229-11, AFX007B-229-17 eAFX007B-229-27 não diferiram significativamente da cultivar Regina 71, ou seja, limbo tipo liso (Tabela 1). As outras 10 famílias obtiveram notas que diferiram significativamente da cultivar Verônica, e não podem ser consideradas de folhas crespas, pois nenhuma apresentou média semelhante à dessa cultivar. Da mesma forma que para borda foliar, houve alta variabilidade tanto entre quanto dentro das famílias, 
o que demonstra, também, a existência de segregação transgressiva em relação ao caráter (Tabela 2).

Como nenhuma das famílias apresentou padrão comercialmente aceito para alface do tipo crespa, ou seja, que não diferisse da cultivar Verônica, é necessário que se realize um ou mais retrocruzamentos com uma cultivar comercial deste tipo, seguidos de novas seleções, para se recuperar o fenótipo comercial de limbo e borda foliares crespos. Em estudo realizado com plantas $\mathrm{F}_{2}$, oriundas do cruzamento entre parentais contrastantes, retrocruzadas com a cultivar Verônica (tipo crespa), foi possível a seleção de linhagens promissoras de alface de folhas crespas e soltas (Fiorini et al., 2005).

Com relação à cor das folhas, as famílias AFX007B-140-06, AFX007B-140-21,AFX007B-150-02, AFX007B-150-18, AFX007B-188-10, AFX007B-229-27 e AFX007B-311-23 foram estatisticamente diferentes

Tabela 1. Média de notas para tipo de borda e limbo foliares e coloração de folhas, e média de dias decorridos desde o transplante até a primeira antese, para as 15 famílias $\mathrm{F}_{4}$ comparadas às cultivares parentais Verônica e Salinas 88 , além das testemunhas Regina 71 e Grand Rapids ${ }^{(1)}$.

\begin{tabular}{|c|c|c|c|c|c|c|c|c|}
\hline \multirow[t]{2}{*}{ Tratamento } & \multicolumn{2}{|c|}{ Borda } & \multicolumn{2}{|c|}{ Limbo } & \multicolumn{2}{|c|}{ Cor } & \multicolumn{2}{|c|}{ Antese } \\
\hline & $\mathrm{T}>$ Verônica & $\mathrm{T}>$ Regina 71 & $\mathrm{~T}>$ Verônica & $\mathrm{T}>$ Regina 71 & $\mathrm{~T}>$ Verônica & $\mathrm{T}>$ Salinas 88 & $\mathrm{~T}>$ Grand Rapids & $\mathrm{T}>$ Regina 71 \\
\hline Verônica & 1,00 & $* *$ & 1,00 & $* *$ & 1,00 & $* *$ & $132,7 * *$ & ns \\
\hline Salinas 88 & $3,00^{* *}$ & $* *$ & $4,00 * *$ & $* *$ & $2,60 * *$ & - & $139,9 * *$ & ns \\
\hline Grand Rapids & $2,00 *$ & $* *$ & $1,12^{\mathrm{ns}}$ & $* *$ & $1,00^{\mathrm{ns}}$ & $* *$ & $108,8 * *$ & $* *$ \\
\hline Regina 71 & $5,00 * *$ & - & $5,00 * *$ & - & $2,20 * *$ & $*$ & $143,6 * *$ & - \\
\hline AFX007B-126-30 & $3,42 * *$ & $* *$ & $4,07 * *$ & $\mathrm{~ns}$ & $1,00^{\mathrm{ns}}$ & $* *$ & $122,7^{*}$ & $* *$ \\
\hline AFX007B-140-06 & $3,47 * *$ & $* *$ & $3,10 * *$ & $* *$ & $2,20 * *$ & ns & $128,0 * *$ & $* *$ \\
\hline AFX007B-140-21 & $3,42 * *$ & $* *$ & $3,72 * *$ & $* *$ & $2,47 * *$ & $\mathrm{~ns}$ & $138,2 * *$ & $\mathrm{~ns}$ \\
\hline AFX007B-150-02 & $2,95 * *$ & $* *$ & $3,05 * *$ & $* *$ & $2,47 * *$ & ns & $125,5 * *$ & $* *$ \\
\hline AFX007B-150-14 & $3,47 * *$ & $* *$ & $3,65 * *$ & $* *$ & $1,02^{\mathrm{ns}}$ & $* *$ & $126,2 * *$ & $* *$ \\
\hline AFX007B-150-18 & $3,30 * *$ & $* *$ & $3,47 * *$ & $* *$ & $2,77 * *$ & $\mathrm{~ns}$ & $134,0 * *$ & $\mathrm{~ns}$ \\
\hline AFX007B-188-10 & $3,27 * *$ & $* *$ & $3,71 * *$ & $* *$ & $2,67 * *$ & ns & $135,0 * *$ & ns \\
\hline AFX007B-188-13 & $2,50 * *$ & $* *$ & $3,60 * *$ & $* *$ & $1,00^{\mathrm{ns}}$ & $* *$ & $140,7 * *$ & $\mathrm{~ns}$ \\
\hline AFX007B-188-14 & $3,35 * *$ & $* *$ & $3,50 * *$ & $* *$ & $1,00^{\mathrm{ns}}$ & $* *$ & $133,3 * *$ & ns \\
\hline AFX007B-229-09 & $4,82 * *$ & $\mathrm{~ns}$ & $4,42 * *$ & $\mathrm{~ns}$ & $1,00^{\mathrm{ns}}$ & $* *$ & $116,7^{\mathrm{ns}}$ & $* *$ \\
\hline AFX007B-229-11 & $4,90 * *$ & ns & $4,95 * *$ & $\mathrm{~ns}$ & $1,00^{\mathrm{ns}}$ & $* *$ & $110,2^{\mathrm{ns}}$ & $* *$ \\
\hline AFX007B-229-17 & $4,17 * *$ & $\mathrm{~ns}$ & $4,27 * *$ & $\mathrm{~ns}$ & $1,00^{\mathrm{ns}}$ & $* *$ & $119,8^{\mathrm{ns}}$ & $* *$ \\
\hline AFX007B-229-27 & $4,85^{* *}$ & ns & $4,32 * *$ & ns & $2,67 * *$ & ns & $118,1^{\mathrm{ns}}$ & $* *$ \\
\hline AFX007B-311-23 & $3,51 * *$ & $* *$ & $3,77 * *$ & $* *$ & $2,60 * *$ & $\mathrm{~ns}$ & $122,8^{*}$ & $* *$ \\
\hline AFX007B-75-05 & $2,22 * *$ & $* *$ & $3,77 * *$ & $* *$ & $1,02^{\mathrm{ns}}$ & $* *$ & $143,0 * *$ & $\mathrm{~ns}$ \\
\hline
\end{tabular}

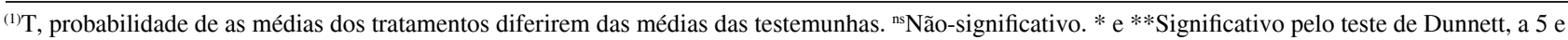
$1 \%$ de probabilidade, respectivamente.

Tabela 2. Distribuição de notas para borda e limbo foliares de plantas de três cultivares e 15 famílias $\mathrm{F}_{4}$ ('Salinas $88^{\prime} \mathrm{x}$ 'Verônica') de alface.

\begin{tabular}{|c|c|c|c|c|c|c|c|c|c|c|}
\hline \multirow[t]{2}{*}{ Tratamento } & \multicolumn{5}{|c|}{$\begin{array}{c}\text { Borda } \\
\text { № de plantas para cada nota }\end{array}$} & \multicolumn{5}{|c|}{$\begin{array}{c}\text { Limbo } \\
\text { № de plantas para cada nota }\end{array}$} \\
\hline & 1 & 2 & 3 & 4 & 5 & 1 & 2 & 3 & 4 & 5 \\
\hline Verônica & 40 & 0 & 0 & 0 & 0 & 40 & 0 & 0 & 0 & 0 \\
\hline Salinas 88 & 0 & 0 & 40 & 0 & 0 & 0 & 0 & 0 & 40 & 0 \\
\hline Regina 71 & 0 & 0 & 0 & 0 & 40 & 0 & 0 & 0 & 0 & 40 \\
\hline AFX007B-126-30 & 0 & 0 & 28 & 7 & 5 & 0 & 3 & 5 & 18 & 14 \\
\hline AFX007B-140-06 & 0 & 1 & 23 & 12 & 4 & 0 & 6 & 24 & 10 & 0 \\
\hline AFX007B-140-21 & 0 & 4 & 15 & 21 & 0 & 0 & 0 & 20 & 11 & 9 \\
\hline AFX007B-150-02 & 0 & 6 & 30 & 4 & 0 & 0 & 7 & 25 & 7 & 1 \\
\hline AFX007B-150-14 & 0 & 1 & 19 & 20 & 0 & 1 & 3 & 13 & 15 & 8 \\
\hline AFX007B-150-18 & 0 & 4 & 20 & 16 & 0 & 0 & 2 & 17 & 21 & 0 \\
\hline AFX007B-188-10 & 1 & 5 & 13 & 11 & 5 & 1 & 3 & 8 & 16 & 7 \\
\hline AFX007B-188-13 & 7 & 14 & 11 & 8 & 0 & 0 & 4 & 12 & 20 & 4 \\
\hline AFX007B-188-14 & 1 & 9 & 8 & 18 & 3 & 1 & 3 & 12 & 22 & 1 \\
\hline AFX007B-229-09 & 0 & 0 & 0 & 7 & 29 & 0 & 0 & 4 & 15 & 17 \\
\hline AFX007B-229-11 & 0 & 0 & 0 & 4 & 36 & 0 & 0 & 0 & 2 & 38 \\
\hline AFX007B-229-17 & 0 & 0 & 5 & 23 & 12 & 0 & 0 & 4 & 21 & 15 \\
\hline AFX007B-229-27 & 0 & 0 & 0 & 6 & 34 & 0 & 0 & 6 & 15 & 19 \\
\hline AFX007B-311-23 & 0 & 0 & 22 & 13 & 3 & 0 & 1 & 11 & 22 & 4 \\
\hline AFX007B-75-05 & 15 & 12 & 6 & 3 & 4 & 0 & 11 & 5 & 6 & 18 \\
\hline
\end{tabular}


da cultivar Verônica e semelhantes à Salinas 88, o que foi indicado pela coloração verde-escura em suas folhas (Tabela 1). O contrário ocorreu com as demais 8 famílias avaliadas, que apresentaram coloração verdeclara, e não diferiram da cultivar Verônica, utilizada como testemunha.

Entre as 15 famílias avaliadas, seis (AFX007B-140-21, AFX007B-150-18,AFX007B-188-10,AFX007B-188-13, AFX007B-188-14 e AFX007B-75-05) apresentaram número médio de dias para o florescimento, que não diferiram de 'Regina 71', tendo sido consideradas resistentes ao florescimento precoce (Tabela 1). As famílias AFX007B-229-09, AFX007B-229-11, AFX007B-229-17 e AFX007B-229-27 apresentaram número médio de dias para o florescimento, que não diferiu de 'Grand Rapids', tendo sido consideradas sensíveis ao calor. As famílias restantes apresentaram valores intermediários, diferidos de ambas as cultivares, com reação média de tolerância ao calor.

Em estudo de herança, que utilizaram cultivares contrastantes quanto à tendência ao florescimento, Silva et al. (1999) e Silveira et al. (2002) observaram a existência de mais de um gene, e a presença de fenótipos superiores aos pais na geração $F_{2}$, o que caracteriza a existência de segregação transgressiva quanto ao caráter. $\mathrm{O}$ maior número de dias para o florescimento, apresentado por algumas progênies $\mathrm{F}_{4}$ (AFX007B-188-13 e AFX007B-75-05) em relação ao melhor dos pais ('Salinas $88^{\prime}$ ), pode ser explicado pela existência de segregação transgressiva quanto ao florescimento (Silva et al., 1999; Ramalho et al., 2004).

Quanto às três características relacionadas à folha, as famílias AFX007B-150-14, AFX007B-188-13, AFX007B-188-14 e AFX007B-75-05 apresentaramse como as mais promissoras, dentro do padrão comercialmente aceito de alface de folhas crespas. Entre essas, as famílias AFX007B-188-13 e AFX007B-188-14 apresentaram-se também como mais tolerantes ao florescimento precoce e, assim, podem ser selecionadas para dar continuidade ao programa de melhoramento genético de alface de folhas crespas, resistentes ao calor.

Quanto à reação ao Meloidogyne javanica, na característica índice visual de galhas (IVG), verificou-se que oito famílias (AFX007B-126-30, AFX007B-140-06, AFX007B-140-21, AFX007B-150-14, AFX007B-188-10, AFX007B-229-17, AFX007B-229-27 e AFX007B-311-23) não diferiram do parental resistente - cultivar Salinas 88 -, porém, diferiram do parental suscetível - cultivar Verônica -, e foram consideradas homozigotas resistentes (Tabela 3). No entanto, seis famílias (AFX007B-150-02, AFX007B-188-13, AFX007B-188-14,AFX007B-229-09,AFX007B-229-11 e AFX007B-75-05) diferiram significativamente do parental resistente, sem, no entanto, diferir do parental

Tabela 3. Reação mais provável, quando se comparam as médias de notas para índice visual de galhas (IVG), número de galhas (NDG) por sistema radicular e incidência de sintomas de Lettuce mosaic virus (LMV), em 15 famílias $\mathrm{F}_{4}$ de alface ('Salinas 88' x 'Verônica') com suas cultivares parentais ${ }^{(1)}$.

\begin{tabular}{|c|c|c|c|c|c|c|c|c|c|}
\hline \multirow[t]{2}{*}{ Famílias } & \multicolumn{3}{|c|}{ IVG } & \multicolumn{3}{|c|}{ NDG } & \multicolumn{3}{|c|}{ LMV } \\
\hline & $\mathrm{T}>$ Salinas 88 & $\mathrm{~T}>$ Verônica & $\begin{array}{c}\text { Reação } \\
\text { provável }\end{array}$ & $\mathrm{T}>$ Salinas 88 & $\mathrm{~T}>$ Verônica & $\begin{array}{c}\text { Reação } \\
\text { provável }\end{array}$ & $\mathrm{T}>$ Salinas 88 & $\mathrm{~T}>$ Verônica & $\begin{array}{l}\text { Reação } \\
\text { provável }\end{array}$ \\
\hline Verônica & $2,487 * *$ & - & HS & $31,666 * *$ & - & HS & $2,875 * *$ & - & HS \\
\hline Salinas 88 & 1,439 & $* *$ & HR & 4,561 & $* *$ & HR & 1,175 & $* *$ & HR \\
\hline AFX007B-126-30 & $1,812^{\mathrm{ns}}$ & $*$ & HR & $5,646^{\mathrm{ns}}$ & $* *$ & HR & $2,125 * *$ & ns & HS \\
\hline AFX007B-140-06 & $1,437^{\mathrm{ns}}$ & $* *$ & HR & $6,979^{\mathrm{ns}}$ & $* *$ & HR & $2,100 * *$ & ns & HS \\
\hline AFX007B-140-21 & $1,687^{\mathrm{ns}}$ & $* *$ & HR & $12,833^{\mathrm{ns}}$ & $* *$ & HR & $1,650^{\mathrm{ns}}$ & $* *$ & HR \\
\hline AFX007B-150-02 & $2,042 *$ & ns & HS & $12,610 * *$ & $* *$ & SG & $1,775^{\mathrm{ns}}$ & $* *$ & HR \\
\hline AFX007B-150-14 & $1,333^{\mathrm{ns}}$ & $* *$ & HR & $14,277^{\mathrm{ns}}$ & $* *$ & HR & $2,325 * *$ & $\mathrm{~ns}$ & HS \\
\hline AFX007B-150-18 & $1,917^{\mathrm{ns}}$ & $\mathrm{ns}$ & SG & $22,333 * *$ & ns & HS & $1,775^{\mathrm{ns}}$ & $* *$ & HR \\
\hline AFX007B-188-10 & $1,687^{\mathrm{ns}}$ & $* *$ & HR & $17,979 * *$ & * & SG & $1,750^{\mathrm{ns}}$ & $* *$ & HR \\
\hline AFX007B-188-13 & $2,100^{*}$ & ns & HS & $18,775^{* *}$ & $*$ & SG & $1,625^{\mathrm{ns}}$ & $* *$ & HR \\
\hline AFX007B-188-14 & $2,026^{*}$ & ns & HS & $14,167 * *$ & $* *$ & SG & $1,675^{\mathrm{ns}}$ & $* *$ & HR \\
\hline AFX007B-229-09 & $2,250 * *$ & ns & HS & $16,536^{*}$ & $*$ & SG & $3,025 * *$ & ns & HS \\
\hline AFX007B-229-11 & $2,229 * *$ & ns & HS & $12,375^{*}$ & $* *$ & SG & $3,125 * *$ & ns & HS \\
\hline AFX007B-229-17 & $1,729^{\mathrm{ns}}$ & $*$ & HR & $18,562 * *$ & $*$ & SG & $2,750 * *$ & ns & HS \\
\hline AFX007B-229-27 & $1,541^{\mathrm{ns}}$ & $* *$ & HR & $9,000^{\mathrm{ns}}$ & $* *$ & HR & $3,000 * *$ & ns & HS \\
\hline AFX007B-311-23 & $1,458^{\mathrm{ns}}$ & $* *$ & HR & $7,881^{\text {ns }}$ & $* *$ & HR & $1,964^{\mathrm{ns}}$ & $* *$ & HR \\
\hline AFX007B-75-05 & $2,075^{*}$ & ns & HS & $27,700 * *$ & ns & HS & $2,018^{\mathrm{ns}}$ & $*$ & HR \\
\hline
\end{tabular}

${ }^{(1)} \mathrm{HS}$, homozigota suscetível; HR, homozigota resistente; SG, segregante; T, probabilidade de as médias dos tratamentos diferirem das médias das testemu-

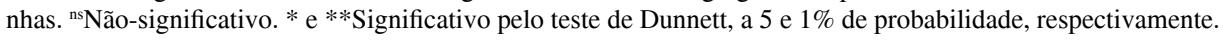


suscetível; assim, foram classificadas como homozigotas suscetíveis. A família AFX007B-150-18 apresentou-se como segregante, por não diferir significativamente de nenhum dos parentais, resistente e suscetível.

Ao se considerar a característica número de galhas (NDG), seis famílias (AFX007B-126-30, AFX007B-140-06,AFX007B-140-21,AFX007B-150-14, AFX007B-229-27 e AFX007B-311-23) apresentaramse como homozigotas resistentes, pois não diferiram da cultivar resistente Salinas 88, porém, diferiram da suscetível Verônica (Tabela 3). Observa-se que todas essas famílias encontram-se entre as oito anteriormente consideradas homozigotas resistentes, quanto à característica de índice visual de galhas. Apenas as famílias AFX007B-150-18 e AFX007B-75-05 foram classificadas como homozigotas suscetíveis para número de galhas. Todas as demais famílias (AFX007B-150-02,AFX007B-188-10,AFX007B-188-13, AFX007B-188-14, AFX007B-229-09, AFX007B-229-11 e AFX007B-229-17) diferiram significativamente de ambos os parentais - resistente e suscetível; assim, foram consideradas segregantes.

A classificação das famílias pelas duas características (índice visual de galhas e número de galhas) foi coincidente para as seis famílias consideradas homozigotas resistentes; na maioria das outras famílias, houve certa discrepância. Quando baseado no índice visual de galhas, elas foram consideradas homozigotas suscetíveis e, ao se contar o número de galhas, foram consideradas segregantes. Como a amplitude de variação entre os parentais é bastante superior quanto à característica número de galhas (4,561 para 'Salinas 88' e 31,666 para 'Verônica'), em relação ao índice visual de galhas (1,439 para 'Salinas 88 ' e 2,487 para 'Verônica'), é possível que, neste último caso, não tenha sido possível observar alguma diferença significativa em relação a ambos os parentais, o que classificaria a família como segregante. No entanto, como já havia sido feita uma seleção para a resistência aos nematóides, era de se esperar que se encontrasse um maior número de famílias resistentes, em vista do modo de herança do caráter (Gomes et al., 2000; Carvalho Filho, 2006).

Com relação ao LMV, das 15 famílias $\mathrm{F}_{4}$ avaliadas (Tabela 3), oito (AFX007B-140-21, AFX007B-150-02, AFX007B-150-18,AFX007B-188-10,AFX007B-188-13, AFX007B-188-14,AFX007B-311-23 e AFX007B-75-05) diferiram significativamente da cultivar suscetível 'Verônica', sem, no entanto, diferir da cultivar resistente 'Salinas 88'. Essas famílias puderam, portanto, ser consideradas homozigotas resistentes quanto ao caráter, uma vez que a resistência ao vírus presente na cultivar Salinas 88 é atribuída a um gene recessivo, em que o alelo $\mathrm{mol}^{2}$ condiciona a resistência (Stangarlin et al., 2000). As outras famílias que se mostraram suscetíveis tanto podem ser homozigotas quanto heterozigotas. Como já havia sido feita uma seleção para a resistência ao LMV, em plantas individuais na geração $\mathrm{F}_{2}$, é importante se fazerem as avaliações em famílias para confirmar a resistência.

\section{Conclusões}

1. A família AFX007B-140-21, homozigota quanto à resistência aos nematóides e ao Lettuce mosaic virus e, também, tolerante ao calor, é mais promissora para o programa de melhoramento.

2. Por meio do cruzamento entre uma cultivar de folhas crespas e soltas com uma de folhas crespas e repolhuda, podem-se originar linhagens promissoras, tanto de folhas crespas quanto de folhas lisas.

\section{Agradecimentos}

Ao Conselho Nacional de Desenvolvimento Científico e Tecnológico, à Fundação de Amparo à Pesquisa do Estado de Minas Gerais e à Fundação de Apoio ao Ensino, Pesquisa e Extensão da Universidade Federal de Lavras, pelo financiamento da pesquisa; à Universidade Federal de Lavras e à HortiAgro Sementes Ltda., pela disponibilização das estruturas para realização do trabalho.

\section{Referências}

AGRIANUAL 2008: anuário da agricultura brasileira. São Paulo: FNP Consultoria \& Comércio, 2007. 159p.

CARVALHO FILHO, J.L.S de. Resistência da alface 'Salinas 88' a Meloidogyne incognita (Kofoid \& White) Chitwood. 2006. 49p. Dissertação (Mestrado) - Universidade Federal de Lavras, Lavras.

CÁSSERES, E. Producción de hortalizas. São José: Instituto Interamericano de Ciências Agrícolas, 1980. 387p.

CHUNG, R.M.; AZEVEDO FILHO, J.A. de; COLARICCIO, A. Avaliação da reação de genótipos de alface (Lactuca sativa L.) ao Lettuce mosaic virus (LMV). Bragantia, v.66, p.61-68, 2007. 
COSSA, A.C.; COLARICCIO, A.; EIRAS, M.; CHAVES, A.L.R. Partial characterization of Lettuce mosaic virus (LMV). Pathotype III in hydroponic lettuce. Virus Reviews and Research, v.5, p.195, 2000.

FIORINI, C.V.A.; GOMES, L.A.A.; LIBÂNIO, R.A.; MALUF, W.R.; CAMPOS, V.P.; LICURSI, V.; MORETTO, P.; SOUZA, L.A. de; FIORINI, I.V.A. Identificação de famílias $\mathrm{F}_{2: 3}$ de alface homozigotas resistentes aos nematóides-das-galhas. Horticultura Brasileira, v.25, p.509-513, 2007.

FIORINI, C.V.A.; GOMES, L.A.A.; MALUF, W.R.; FIORINI, I.V.A.; DUARTE, R. de P.F.; LICURSI, V. Avaliação de populações $\mathrm{F}_{2}$ de alface quanto à resistência aos nematóides-das-galhas e tolerância ao florescimento precoce. Horticultura Brasileira, v.23, p.299-302, 2005.

GOMES, L.A.A.; MALUF, W.R.; CAMPOS, V.P. Inherintance of the resistant reaction of the lettuce cultivar 'Grand Rapids' to the southern root-knot nematode Meloidogyne incognita (Kofoid \& White) Chitwood. Euphytica, v.114, p.37-46, 2000.

MALUF, L.E.J.; OKADA, A.T.; GOMES, L.A.A.; FIORINI, C.V.A.; MALUF, W.R.; LICURSI, V. Reação de cultivares de alface à infecção por Meloidogyne incognita. In: CONGRESSO BRASILEIRO DE OLERICULTURA, 43., 2003, Recife. Anais. Recife: UFRPE, 2003. CD-ROOM.

NAGAI, H. Obtenção de novas cultivares de alface (Lactuca sativa L.) resistentes ao mosaico e ao calor: Brasil-303 e 311. Revista de Olericultura, v.18, p.14-21, 1980.
NAGAI, H. Obtenção de novos cultivares de alface (Lactuca sativa L.) resistentes ao mosaico e ao calor. I-Brasil 48, 202 e 221. Revista de Olericultura, v.17, p.129-137, 1979.

NAGAI, H.; COSTA, A.S. Incorporação de resistência ao vírus de mosaico em alface do tipo manteiga. Arquivos do Instituto Biológico, v.38, p.95-98, 1971.

PINK, D.A.C.; KOSTAVA, D.; WALKEY, D.G.A. Differentiation of pathotypes of Lettuce mosaic virus. Plant Pathology, v.41, p.5-12, 1992.

RAMALHO, M.A.P.; SANTOS, J.B. dos; PINTO, C.A.B.P. Genética na agropecuária. 3.ed. rev. Lavras: Ufla, 2004. 472p.

SILVA, E.C.; MALUF, W.R.; LEAL, N.R.; GOMES, L.A.A. Inheritance of bolting tendency in lettuce Lactuca sativa L. Euphytica, v.109, p.1-7, 1999.

SILVEIRA, M.A.; ANDRÉ, C.M.G.; NOGUEIRA, S.R.; SATANA, W.R. Seleção de progênies de alface contra o pendoamento precoce e resistência aos nematóides-das-galhas Meloidogyne spp. em condições de campo. Horticultura Brasileira, v.20, p.278, 2002. (Suplemento 2).

STANGARLIN, O.; PAVAN, M.A.; SILVA, N. da. Occurrence of a new pathotype of Lettuce mosaic virus on lettuce in Brazil. Plant Disease, v.84, p.490, 2000.

Recebido em 26 de fevereiro de 2008 e aprovado em 19 de setembro de 2008 